\title{
ОПТИМИЗАЦИЯ УСЛОВИЙ ИЗОЭЛЕКТРОФОКУСИРОВАНИЯ В ПОЛИАКРИЛАМИДНОМ ГЕЛЕ
}

\section{Введение}

Изоэлектрофокусирование (ИЭФ) белков в полиакриламидном геле в настоящее время - один из самых перспективных методов разделения белков в силу экспрессности, точности и большой разрешающей способности.

Қак известно, для создания естественного градиента $\mathrm{pH}$ до сих пор применялись дорогостоящие и малодоступные амфолиты-носители фирм ЛКБ, «Фармация» (Швеция), и «Серва» (ФРГ). Синтез отечественных амфолитов-носителей «Мурсилайт Т» ['] значительно увеличивает возможность применения метода ИЭФ в СССР, но вместе с тем и выдвигает новые задачи: исследование свойств новых амфолитовносителей, определение оптимальных условий эксперимента и режима работы на приборе. Постановка таких задач диктуется химической структурой «Мурсилайта Т» отличной от структур западных амфолитовносителей. Поэтому при ИЭФ в полиакриламидном геле с использованием «Мурсилайта Т» мы должны проанализировать рекомендации, предложенные в проспектах фирм ЛКБ, «Фармация» и «Серва».

Данная работа поэтому целиком посвящается рассмотрению оптимальных условий ИЭФ в полиакриламидном геле с использованием «Мурсилайта Т» и сравнению свойств коммерческих амфолитов-носителей и «Мурсилайта Т».

\section{Материалы и методы}

Приготовление геля. Для приготовления геля использовались нестандартные рамки размером $25 \times 105$ мм. Рамки представляют собой две пластинки из оргстекла, между которыми помещаются пленка и резиновая прокладка. Принцип действия аналогичен предложенному в проспекте фирмы ЛКБ. 0,325 г акриламида и 0,011 г $\mathrm{N}, \mathrm{N}^{\prime}$-метиленбисакриламида растворяют в небольшом количестве дистиллированной воды. K полученному раствору добавляют 0,50 мл глицерина, 0,01 мл $\mathrm{N}, \mathrm{N}, \mathrm{N}^{\prime}, \mathrm{N}^{\prime}$-тетраметилэтилендиамина (ТЕМЕД) и 0,33 мл $40 \%$-ного раствора амфолитов-носителей. Раствор дегазируют в течение 15 мин в эксикаторе, соединенном с водоструйным насосом. Затем добавляют 0,5 мл $0,1 \%$-ного раствора катализатора $\left(\mathrm{NH}_{4}\right)_{2} \mathrm{~S}_{2} \mathrm{O}_{8}$ и объем раствора доводят до 5 мл. Полученный раствор $(T=6,7 \% ; C=1,9 \%)$ заливают в рамку для приготовления геля.

Прибор для ИЭФ. Для проведения ИЭФ применялся прибор «Мультипор-2117» фирмы ЛКБ. Расстояние между электродами 10 см. 
Измерение градиента рН. Эту операцию проводили на «рН-метре 340 » следующим образом: по окончании процесса ИЭФ пластинку геля вынимали из прибора и разрезали на 9-10 равных частей. Кусочки геля помещали в специально подготовленные пробирки, содержащие по 2 мл 0,1 M раствора $\mathrm{KCl}$. По истечении 10-15 мин проводили измерение $\mathrm{pH}$. Это точный и достаточно быстрый метод измерения $\mathrm{pH}$. Попытка использовать для этой цели поверхностный электрод $\mathrm{Sb} / \mathrm{Sb}_{2} \mathrm{O}_{3}\left[{ }^{2}\right]$ не дала положительных результатов. Во-первых, при калибровке электрода $\mathrm{Sb} / \mathrm{Sb}_{2} \mathrm{O}_{3}$ график зависимости от $\mathrm{pH}$ оказался линейным лишь в области, обольшей 7,0 , а в области $5,0-7,0$ наблюдается плато. Во-вторых, установление стабильности показаний прибора происходит в течение 15-20 мин и в значительной степени зависит от температуры измеряемого объекта. В силу этих обстоятельств нам пришлось отказаться от применения поверхностного электрода $\mathrm{Sb} / \mathrm{Sb}_{2} \mathrm{O}_{3}$.

Измерение электропроводности. С этой целью использовали кондуктометр ОК-102/1 (ВНР). Как и для $\mathrm{pH}$, для измерения электропроводности после ИЭФ гель разрезали на кусочки. Кусочки геля помещали в пробирки, содержащие по 2 мл дистиллированной воды. По истечении 3 ч проводили измерение электропроводности.

Определение буферной емкости. Нарезанные кусочки геля взвешивали на аналитических весах с точностью до 0,01 г и помещали в пробирки с дистиллированной водой $(2$ мл). Гель выдерживали таким образом $20-30 м и н$, а затем в пробирки добавляли $0,2-0,6$ мл $0,1 \mathrm{M}$ раствора KOH. Полученные растворы оттитровывали на «рН-метре $340 » 0,1 M$ раствором $\mathrm{HCl}$. При расчете буферной емкости разбавление при титровании мы принимали за постоянную величину, а величину разбавления в расчетах не учитывали.

\section{Сравнение свойств «Мурсилайта Т» со свойствами западных амфолитов-носителей}

Прежде чем приступить к оптимизации условий ИЭФ, необходимо провести сравнение свойств «Мурсилайта Т» и западных амфолитов-носителей, уже зарекомендовавших себя на мировом рынке. Наиболее важными характеристиками являются такие параметры, как буферная емкость и электропроводность (рис. 1). Как показывает рис. 1, буферная емкость «Мурсилайта Т» незначительно отличается от буферной емкости «Сервалита» и, во всяком случае, не уступает последней. Электропроводность «Мурсилайта Т» немного ниже, чем западных амфолитов-носителей (рис. 2). Пониженная электропроводность дает возможность прикладывать более высокое напряжение, а следовательно, и получать лучшее разделение белков на фракции. По своей химической структуре «Мурсилайт Т» наиболее близок шведскому «Амфолину», однако, синтезирован на базе более низкомолекулярного амина, сшитого $\mathrm{N}, \mathrm{N}^{\prime}$-метиленбисакриламидом и отличающегося от «Амфолина» и «Сервалита» наличием амидных связей. Молекулярновесовое распределение «Мурсилайта T» ['] существенно отличается от молекулярно-весового распределения западных препаратов, исследованных в работе [3]. «Мурсилайт Т», в отличие от коммерческих препара̀тов, содержит цветные примеси, но этот факт не имеет значения для анализа белковых зон при проявлении полиакриламидных пластин красителями. 

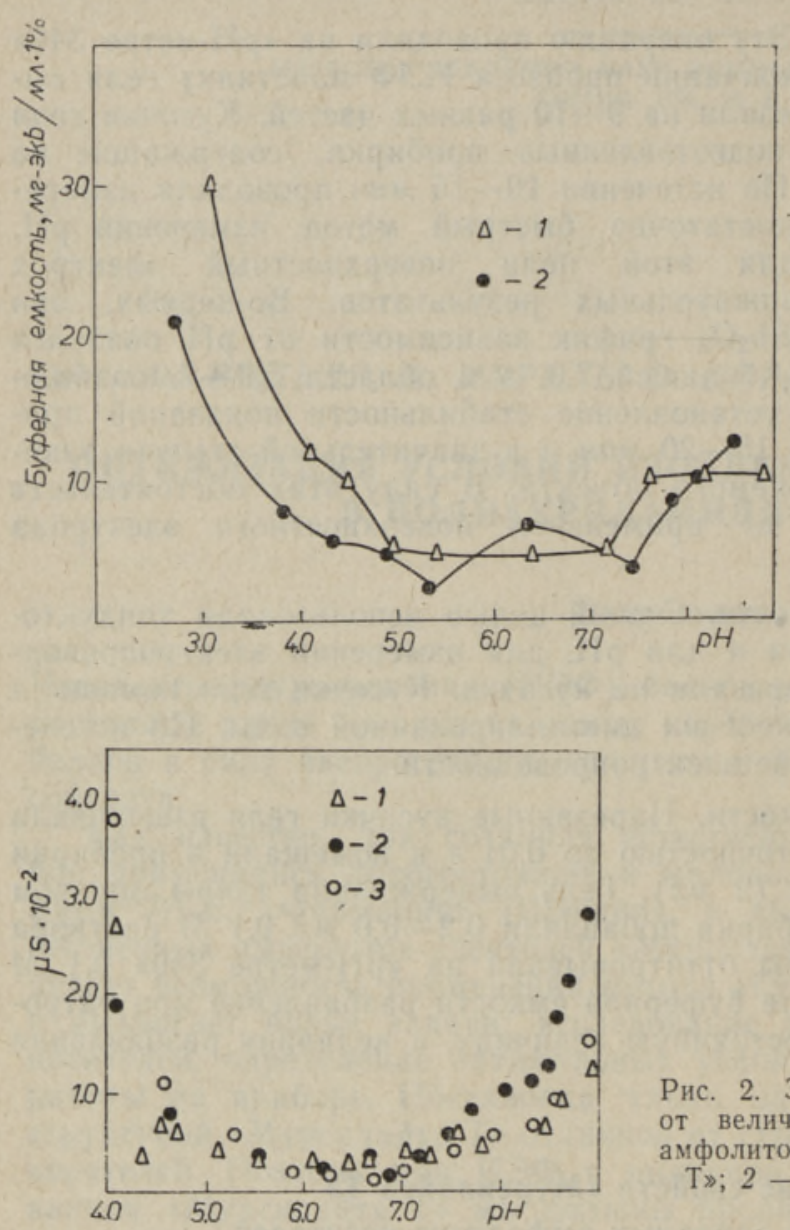

Рис. 1. Зависимость буферной емкости от величины $\mathrm{pH}$ для сфокусированных амфолитов-носителей. 1 - «Мурсилайт Т»; 2 - «Сервалит».

Рис. 2. Зависимость электропроводности от величины $\mathrm{pH}$ для сфокусированных амфолитов-носителей. 1 «Мурсилайт Т»; 2 - «Сервалит»; 3 - «Фармалит».

\section{Выбор оптимальных условий изоэлектрофокусирования}

Для выбора оптимальных условий ИЭФ был проведен ряд экспериментов с целью выявления зависимости градиента $\mathrm{pH}$ от концентрации и состава электролитов, концентрации амфолитов в геле, способа приготовления геля; рассмотрен процесс становления градиента $\mathrm{pH}$ во времени. Для проведения ИЭФ нами предложен следующий режим работы (рис. 3) при объеме геля $25 \mathrm{~cm}^{3}$. Устанавливаем ток 30 мA, который контролирует подаваемое на пластину напряжение. Со временем напряжение постепенно увеличивается до 1,5 $\kappa B$. По достижении мощности $25 B$ начинается падение тока, с этого момента напряжение контролируется величиной мощности.

Зависимость градиента pH от концентрации электролитов (рис. 4) изучалась на примере $\mathrm{NaOH}$ и $\mathrm{H}_{3} \mathrm{PO}_{4}$. При увеличении концентрации этих электролитов наблюдается сужение линейной области градиента $\mathrm{pH}$ и значительно увеличивается способность пластины геля коробиться. Оптимальная концентрация электролитов составляет 0,05 $\mathrm{M}$. При дальнейшем ее уменьшении наблюдается незначительное нарушение линейности градиента.

Зависимость градиента $\mathrm{pH}$ от состава электролитов показана на рис. 5. При применении в качестве электролита более слабой кислоты, 
Рис. 3. График изменения тока и напряжения в процессе ИЭФ (характер изменения напряжения для расстояния между электродами 10 см всегда один и тот же, характер изменения тока зависит от объема геля). 1 - на. пряжение; 2 - ток.

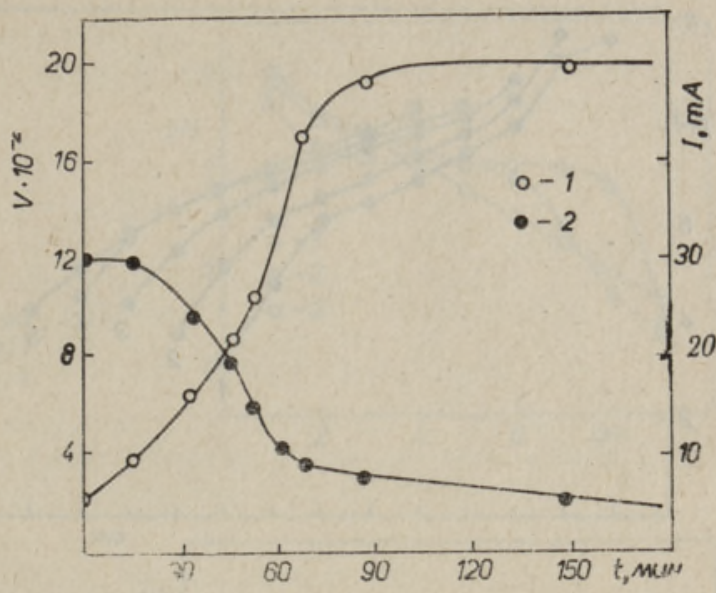

Рис. 4. Зависимость градиента $\mathrm{pH}$ от концентрации электролитов $\mathrm{NaOH}$ и $\mathrm{H}_{3} \mathrm{PO}_{4} \cdot 1-$ концентрации электролитов $\mathrm{NaOH}$ и $\mathrm{H}_{3} \mathrm{PO}_{4}$ соответственно равны $1,5 M$ и $1,5 \mathrm{M} ; 2-$ $1,0 M$ и $1,0 M ; 3-0,1 M$ и $0,1 M ; 4-0,05 M$ и $0,05 M ; 5-0,05 M$ и $0,025 M ; 6-0,05 M$ и $0,01 M$. Кривые сдвинуты по оси абсцисс относнтельно друг друга на 1 cм.

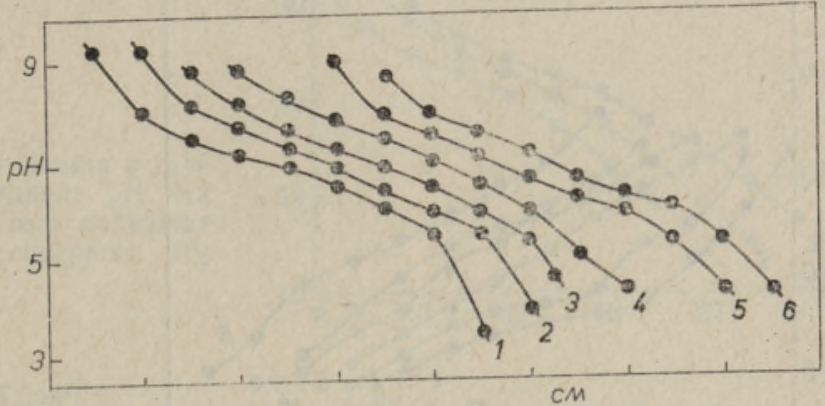

Рис. 5. Зависимость градиента $\mathrm{pH}$ от состава электролита. 1 электролиты $0,1 M \mathrm{NaOH}$ и $0,1 M$ $\mathrm{H}_{3} \mathrm{PO}_{4} ; 2-0,5 \%$-ный ТЕМЕД и $0,5 \%$-ная лимонная кислота; 3 - 1\%-ный ТЕМЕД и 1\%-ная лимонная кислота; $4-0,5 \%$-ный ТЕМЕД и $0,5 \%$-ная лимонная кислота; $5-0,5 \%$-ный ТЕМЕД и $0,05 M \quad \mathrm{H}_{3} \mathrm{PO}_{4}$. Кривые сдвинуты вдоль оси абсцисс относительно друг друга на 1 см.

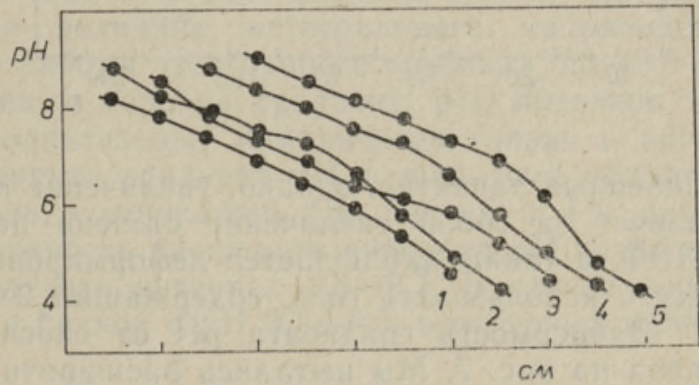

например лимонной, наблюдается явное изменение тангенса угла наклона графика в области $\mathrm{pH} 3-5$. При замене $\mathrm{NaOH}$ на TЕMЕД никаких видимых изменений $\mathrm{pH}$ не происходит. Использование в качестве электролитов кислых и щелочных амфолитов-носителей в нашем случае нецелесообразно, так как сужается кислая область градиента pH. Поэтому мы остановились на использовании в качестве электролитов $0,05 M \mathrm{NaOH}$ и $0,05 \mathrm{M} \mathrm{H}_{3} \mathrm{PO}_{4}$.

При изучении зависимости градиента $\mathrm{pH}$ от концентрации амфолита в геле $0,5-10 \%$ (рис. 6) выяснилось, что градиент $\mathrm{pH}$ незначительно зависит от концентрации. При малых концентрациях происходит отклонение градиента $\mathrm{pH}$ от линейного, при больших сохраняется его 


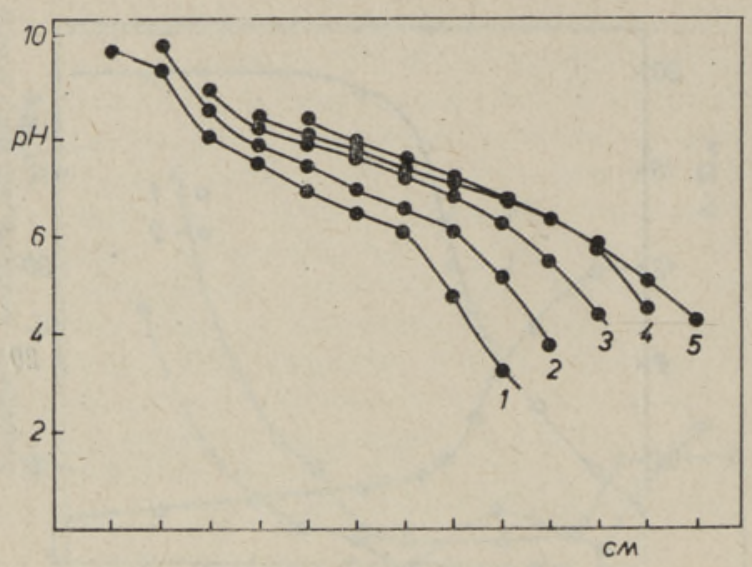

Рис. 6. Зависимость градиента $\mathrm{pH}$ от концентрации амфолитов-носителей в геле. 1 - концентрация амфолитов-носителей в геле $0,5 \% ; 2-1 \% ; 3-$ $3 \% ; 4-5 \% ; 5-10 \%$. Кривые сдвинуты вдоль оси абсцисс относительно друг друга на $1 \mathrm{cs}$.

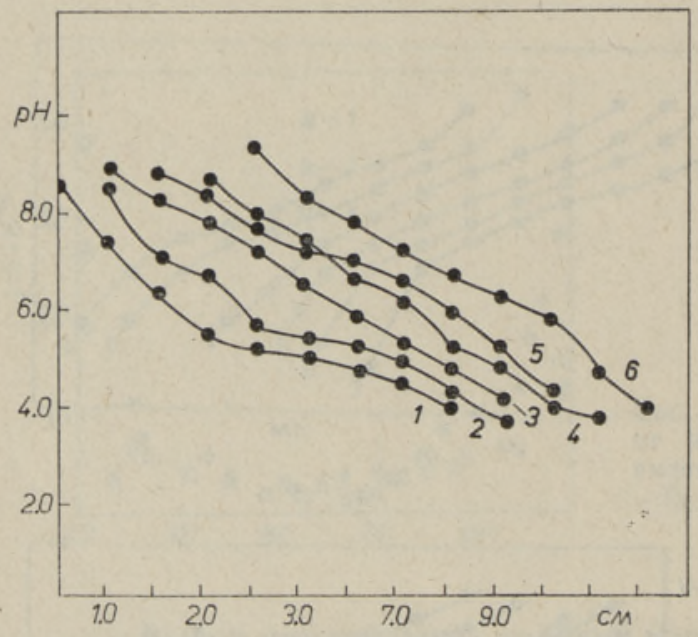

Рнс. 7. Зависимость градиента $\mathrm{pH}$ от концентрации раствора для насыщения. 1 - концентрация раствора для насыщения $0,5 \% ; 2$ $1 \% ; 3-2 \% ; 4-3 \% ; 5-5 \%$; $6-10 \%$.

линей:ый характер, однако, увеличение концентрации амфолитов в геле влечет за собой увеличение степени перегрева пластины в процессе ИЭФ, а также наблюдается деформирование пластины. Поэтому лучше всего использовать гель, содержащий $2-5 \%$ «Мурсилайта Т».

Зависимость градиента $\mathrm{pH}$ от способа приготовления геля приведена на рис. 7. Мы пытались расширить интервал градиента рН путем изменения способа приготовления геля. Гель, не содержащий амфолитов-носителей, насыщался в растворе амфолитов-носителей [ $\left.{ }^{4}\right]$. Концентрацию раствора изменяли от 0,5 до $10 \%$. При насыщении геля в разбавленных растворах «Мурсилайта Т» линейный градиент не создается (рис. 7). Наиболее близкий к прямолинейному градиент получается при насыщении геля в 5-10\%-ном растворе. Однако при таком способе приготовления геля, не получая улучшения градиента, значительно увеличиваем расход амфолитов-носителей. Поэтому мы рекомендуем пользоваться обычным способом приготовления геля.

Становление градиента $\mathbf{p H}$, как известно, есть процесс временно́й. Динамику становления градиента во времени можно проследить по рис. 8. Как показывает график, линейный градиент при вышеуказан- 
Рис. 8. Становление градиента рН во времени. 1 - характер изменения $\mathrm{pH}$ после 30 мин ИЭФ; 2 - после 1 ч ИЭФ; 3 - после 2 ч ИЭФ.
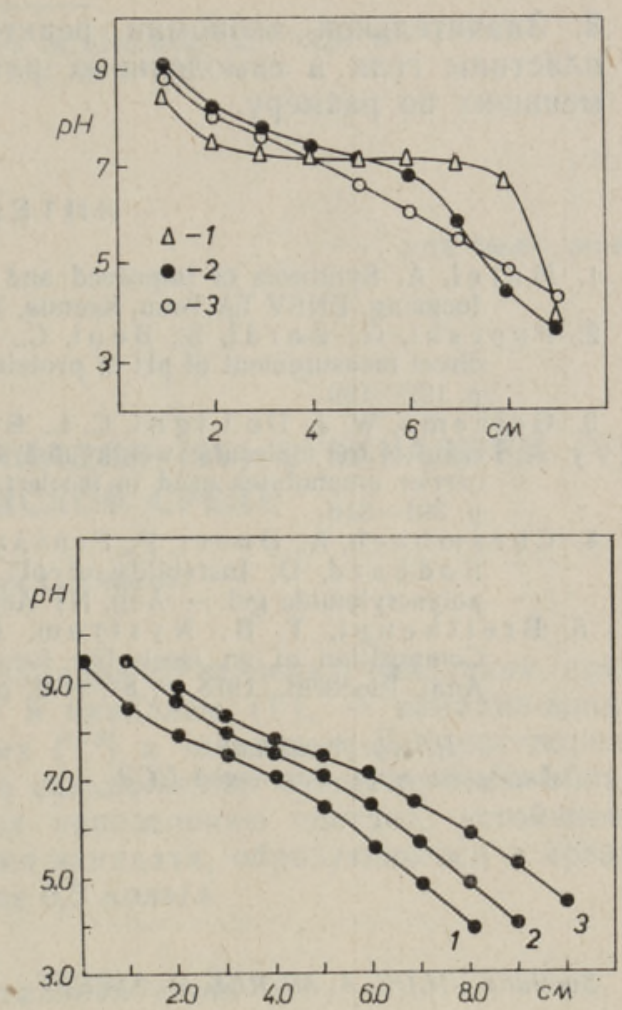

Рис. 9. Влияние аргинина и лизина в геле на градиент $\mathrm{pH} .1$ - градиент $\mathrm{pH}$ без присутствия добавок; 2 - гель содержит $1 \%$ лизина; 3 - гель содержит $1 \%$ аргинина.

ном режиме работы образуется за $1,5-2,0$ ч. Линейность градиента сохраняется в течение $2,0-2,5$ ч до тех пор, пока интегральное напряжение не достигнет величины 4500 B. ч. Для полного разделения белков на фракции достаточна величина интегрального напряжения 3700 В. . При нашем режиме работы этот процесс требовал $3,0-3,5$ и.

Влияние лизина и аргинина в геле на градиент $\mathrm{pH}$ показано на рис. 9. Введением в гель дополнительных компонентов (лизин и аргинин) [5] мы попытались расширить градиент $\mathrm{pH}$ в щелочной области. Для опытов использовали гель, содержащий $1 \%$ лизина и $1 \%$ аргинина. Такой способ дает возможность расширить интервал $\mathrm{pH}$ на 0,5 ед. в щелочной области, т. е. получить интервал $3,0-9,5$. В случае необходимости проведения анализа белков с $\mathrm{pH} 9,1-9,5$, этот прием может быть применен.

\section{Выводы}

1. Для создания устойчивого линейного градиента $\mathrm{pH}$ в полиакриламидном геле рекомендуется использовать $2-5 \%$-ный раствор «Мурсилайта Т» и $0,05 \mathrm{M}$ растворы $\mathrm{NaOH}$ и $\mathrm{H}_{3} \mathrm{PO}_{4}$ в качестве электролитов. В этих условиях наименее заметны механические изменения пластины геля в процессе изоэлектрофокусирования.

2. Белки достигнут своих изоэлектрических точек и сфокусируются в них, когда величина интегрального напряжения приблизится к $3700 \mathrm{~B}$. При рекомендуемом режиме работы стабильность градиента $\mathrm{pH}$ сохраняется до этого момента времени. Заметное разрушение линейного градиента происходит значительно позже. 
3. Значительной экономии реактивов можно достичь, приготовляя пластины геля в самодельных рамках, аналогичных фирменным, но меньших по размеру.

\title{
ЛИТЕРАТ У РА
}

1. Murel, A. Synthesis of improved and inexpensive carrier ampholites for isoelectric focusing. ENSV TA Toim. Keemia, 1980, v. 29, N 3, p. 201-209.

2. Papeshi, G., Bordi, S., B eni, C., Ventura, L. Use of irridium electrode for direct measurement of $\mathrm{pH}$ of proteins after IF in PAA gels. - BBA, 1976, N 453, p. $192-199$.

3. Gelsem a, W, J., De Lig n i, C. L., B l a n ke n, W. M. Gel chromatographic comparison of the molecular weight distribution of ampholine, servalyte and pharmalvte carrier ampholytes used in isoelectric focusing. - J. Chromatogr., 1980, N 198, p. $301-316$.

4. Chr a m b a ch, A., D o e r r, P., Finla y s on, G. R., Miles, L. E. Mi., Sherins, R, $\mathrm{Rodb}$ a rd, D. Instability of $\mathrm{pH}$ gradients formed by isoelectric focusing in polyacrylamide gel. - Ann. NY Acad. Sci., 1973, v. 209, p. 44-64.

5. Breithaupt, T. B., Nystrom, I. E., Hadges, D. H., B abitch, I. A Composition of an isoelectric focusing gel yielding a broad $\mathrm{pH}$ gradient. Anal. Biochem., 1978, v. 84, N 2, p. 579-582.

\author{
Ннститут химии \\ Академии наук Эстонской ССР \\ Поступила в редакцию \\ 16/III 1981
}

Svetlana VILDE, A. MUREL, O. KIRRET

\section{POLUAKRUULAMIIDGEELIS TOIMUVA ISOELEKTRILISE FOKUSEERIMISE TINGIMUSTE OPTIMEERIMINE}

Artiklis on kirjeldatud uue, isoelektriliseks fokuseerimiseks sobiva kandeamfolüüdi «Mursilyte-T» mõningaid füüsikalis-keemilisi omadusi. $\mathrm{pH}$ gradiendi kúju puhul on arvestatud eksperimendi tingimusi: fokuseerimise aega, voolutugevust, pinget, elektrolüüdi kontsentratsiooni, kandeamfolüüdi kontsentratsiooni. On esitatud optimaalsed tingimused isoelektriliseks fokuseerimiseks polüakrüülamiidgeeli plaatides.

Svetlana VILDE, A. MUREL, O. KIRRET

\section{OPTIMIZATION OF ISOELECTROFOCUSING CONDITIONS IN POLYACRYLAMIDE GEL PLATES}

The present paper describes some physico-chemical properties of the new carrier ampholytes - «Mursilyte-T» - suitable for isoelectrofocusing. The shape of the $\mathrm{pH}$ gradient running conditions: focusing time, voltage, current, electrolyte concentration, carrier ampholyte, concentration. Optimum focusing conditions are suggested for isoelectric focusing in polyacrylamide gel plates. 